\title{
Prevention of Incisional Hernia: What is new?
}

\author{
Dhananjaya Sharma* \\ Department of Surgery, India \\ *Corresponding author: Dhananjaya Sharma, Department of Surgery, India
}

Submission: 俔 November 19, 2018; Published: 眥 December 19, 2018

\begin{abstract}
Incisional hernia $(\mathrm{IH})$ is among the commonest post-operative complication after midline laparotomy. In spite of all technological advances its incidence remains 5-26\%; prompting surgeons to think about IH prevention techniques. A scrutiny of factors associated with IH clearly shows that most of these are patient related and are beyond the Surgeon's control. However, there are a few Surgeon-related preventive measures which can help in bringing down the incidence of IH. These include efforts directed at reducing surgical site infection, preferred use of laparoscopy over conventional open surgery, preferred use of transverse incision, using current recommendations for midline laparotomy closure, incisional reinforcement in high risk groups by prophylactic mesh, special incisions/ techniques for prevention of IH in special circumstances, identification of high-risk cases and their centralized care, and increasing awareness of safety of synthetic mesh in presence of infection and strangulation. This brief review is based on relevant published literature in 'PubMed' and 'Google Scholar' since 2013. Now that it is possible to identify high risk patients for development of IH, high quality evidence is available for its prevention and the preventive measures do not require expansive resources; time has come to convert available knowledge to implementation.
\end{abstract}

Keywords: Incisional hernia; Risk factors; Prevention

\section{Introduction}

Secure abdominal wall closure after any laparotomy is every surgeon's aim. Despite numerous improvements over the years in suture materials and closure techniques, the incidence of incisional hernia (IH) has not diminished; and 5-26\% of patients develop IH after midline laparotomy. This figure goes further up if high risk groups are analyzed separately or if the follow up is for a period longer than 3years or when imaging techniques are employed to look for IH. IH imposes significant healthcare burden, > 300,000IH repairs are done in US alone with an estimated cost of $>3.2$ Billion Dollars [1]. Magnitude of this problem has prompted the surgeons to think about IH prevention techniques [2]. The present brief point-wise, reader friendly review is based on relevant published literature in 'PubMed' and 'Google Scholar' since 2013.

\section{Risk Factors for Development of IH After a Midline} Incision

These factors are well known and have entered in to surgical folklore: male gender, age > 60years, preoperative anemia, preoperative hypoproteinemia, Body Mass Index $>25$, abdominal wall thickness $>20 \mathrm{~mm}$, higher visceral and subcutaneous fat, non-elective admission and surgery, co-morbidities, diabetes, malignancy, history of smoking, chronic obstructive pulmonary disease, jaundice, liver disease, ascites, chronic kidney disease, preoperative chemotherapy, previous laparotomy, previous IH, aortic aneurism surgery, bowel surgery, bariatric surgery, creation of an ostomy, closure/ reversal of stoma, longer operative time, increased blood loss during surgery, blood transfusion, suture to wound length ratio $<4$, superficial and deep surgical site infections, wound contamination classification III/ IV, American Society of Anesthesiologists score 3 or 4 points, ventilatory support, immunosuppression therapy, wound dehiscence, postoperative pulmonary problems, postoperative abdominal distension/ intestinal obstruction, postoperative catecholamine-therapy, low institutional surgical volumes and disturbed wound healing.

\section{What can be done to Prevent IH?}

A scrutiny of factors associated with IH clearly shows that most of these are patient related and are beyond the Surgeon's control. Community based anti-obesity and anti-smoking campaigns can reduce obesity and chronic obstructive pulmonary diseases so risks of these two factors can be brought down.

However, there are a few Surgeon-related preventive measures which can help in bringing down the incidence of IH:

\section{Surgical site infection (SSI)}

SSI is among the most important factors-raising the risk of development of IH by 2-10 times-this fact has been known for long and confirmed by several recent studies. Most risk factors for SSI are common with those of development of IH and reducing SSI is an important preventing measure for IH. Compared with superficial SSI, deep SSIs are more strongly associated with the development of IH [3]. A long stitch length is associated with an increase in the 
rate of wound infection and $\mathrm{IH}$; this fact has been known for long and has contributed to the evolution of small stitches for abdominal wall closure.

In trying to reduce SSI, it is worth remembering Halsted's basic principles of surgical technique introduced in late $19^{\text {th }}$ century regarding tissue handling: gentle handling of tissue, meticulous hemostasis, preservation of blood supply, strict aseptic technique to minimize contamination of wound, minimum tension on tissues during closure, accurate tissue apposition and obliteration of dead space. As expected, laparoscopic surgery is associated with a lower incidence of SSI.

World Health Organization and Center for Disease Control guidelines are now available for the prevention of SSIs [4,5]. These include: pre-surgery full body bath with soap, timely antimicrobial prophylaxis as indicated, skin preparation in the operating room using an alcohol-based agent, maintenance of glycemic control, normothermia, peri-operative oxygen saturation and transfusion of blood products as required. Meaningful reductions in SSI can be achieved by implementing such multidisciplinary care bundle at a hospital-wide level [6].

Appropriate antibiotic prophylaxis can reduce the incidence of SSI by as much as $75 \%$. High quality evidence shows that antibiotics covering aerobic and anaerobic bacteria delivered orally or intravenously (or both) prior to elective colorectal surgery reduce the risk of surgical wound infection $[7,8]$. Recently combination of probiotics with antibiotics has been shown to reduce SSIs in colorectal Surgery [9].

Topical antimicrobial prophylaxis, before or after operative wound closure; have shown effectiveness in decreasing SSI, but the quality of evidence is very low to moderate $[10,11]$. Antibioticimpregnated sutures for abdominal fascial closure have been tried to prevent SSIs, hernias, and/or dehiscence but the evidence is ambiguous $[12,13]$. SSIs appear to be reduced with subcutaneous suction drains in open abdominal surgery [14].

\section{Laparoscopy}

Advent of and increasing use of laparoscopy has resulted in marked decrease in incidence of IH-across all surgical indications. However, using laparoscopy is not without port-site incisional herniation. A review found overall incidence of port-site incisional hernia as $1.7 \%$ (range, $0.3 \%$ to $5.4 \%$ ). The most important factors were older age, higher body mass index, preexisting hernia, trocar design, trocar diameter, increased duration of surgery, and extension of the port site for gallbladder extraction. Awareness of the predisposing factors and modification of closure techniques may help to reduce the risk [15]. As expected, single-incision laparoscopic urgical procedures, using larger ports/ incisions have higher port-site hernia rate of $2.9 \%$ at 30 to 36 months' followup [16]. Port sites of $10 \mathrm{~mm}$ and larger diameter fascia should be closed by suture, whereas the risk of hernia development in $5 \mathrm{~mm}$ trocar placements seems to be a rare complication [17].

\section{Type of incision}

Upper midline incision is known for increased IH [18]. Use of a transverse incision for laparotomy (as compared to a midline laparotomy) and use of a transverse incision, in cases of hand assisted laparoscopy or incision to remove specimen is followed by a significant decrease in the incidence of IH [19-21].

\section{Current recommendations for midline laparotomy closure}

These are in favor of continuous, single layer aponeurotic suture with slowly absorbable or non-absorbable monofilament suture material using the small bites technique which has shown significantly less IHs than a large bites technique. Advantage of small bite technique was known for quite some time, but the clinching evidence was provided by STITCH trial and this soon became part of current guidelines [19,22-24]. A large multicenter randomized control trial is going on as a follow up to STITCH trial and results are expected in 2019 [25].

This recent success of small stitch trial has questioned the traditional guideline of 4-4.9:1 relationship between suture and wound length, as it requires a much longer suture. However, concerns have been raised about effective implementation of appropriate suture to incision ratio and extra attention to fascial closure needs to be inculcated among the surgeons [26,27].

Currently, a trial is going on using the 'Hughes/ Cardiff Repair' which combines a standard mass closure with a series of horizontal and two vertical mattress sutures within a single suture [28]. This, theoretically, distributes the load along the incision length as well as across it. However, this involves the use of two sutures, has the risk of bowel trapping and risk of suture entanglement, takes longer time, longer suture, and adds to the cost.

Recently a 'Herring bone' suturing technique has been published which relies on each successive suture to reduce the tension on the stitch for the next suture to be passed [29]. Herring bone suturing technique has the advantage of both continuous and cross suture methods; it is technically easy, reproducible, safe and can be performed quickly.

\section{Incisional reinforcement in high risk groups by prophylactic mesh}

From small comparative studies to large multicenter RCTs and systemic reviews-all have shown that use of prophylactic mesh in high risk groups can significantly reduce the incidence of $\mathrm{IH}$ for midline laparotomy closure (up to $85 \%$ ) as well as for stoma construction (up to 65\%) and stoma closure without adding to the risks of postoperative morbidity, wound-related morbidity, surgical site infection, hematoma, wound disruption, postoperative mortality, chronic pain and length of hospital stay; and is costeffective [30-33]. However, there is no evidence to support the use of biologic/biosynthetic meshes for this purpose [34-36]. Retro-muscular and onlay, both positions of a prophylactic mesh 
seem equally effective and safe for closure of midline laparotomies. Incidence of stoma related IHs can be as high as $>50 \%$, prompting the evolution of guidelines and special techniques for using prophylactic mesh in stoma creation for both open and laparoscopic techniques [37-39]. Polypropylene prophylactic mesh placement patients are at increased risk for seroma; however, glue fixation of mesh can overcome the problem of seroma formation [40].

\section{Special incisions/ techniques for prevention of $\mathrm{IH}$}

Change of conventional hockey-stick incision for Renal Transplantation to the smallest possible semilunar line incision in the inguinal region aids in preventing post-transplantation incisional hernias [41]. A meta-analysis has shown that extraperitoneal colostomy leads to a lower rate $(6.3 \%$ versus $17.8 \%$; $\mathrm{p}<0.001$ ) of para-stomal hernia, as compared to trans-peritoneal colostomy [42]. But a randomized trial assessing the outcome of lateral para-rectus abdominis compared with trans-rectus abdominis muscle stoma placement in patients with temporary loop ileostomies did not show any difference in their para-stomal hernia rates [43]. Special techniques have been described for placement of a pelvic mesh to prevent perineal hernia after any abdomino-perineal resection of rectum [44].

Three time-honored techniques used for prevention of $\mathrm{IH}$ for years - abdominal binders after laparotomy, restrictions on physical activity after laparotomy, and use of retention sutures - but no scientific benefit/ evidence has been found for their use [45-47].

\section{Special risks for IH with different operations}

The overall incidence of IH for Inflammatory Bowel Disease operations has been shown to be $21 \%$ for ulcerative colitis and $20 \%$ for Crohn's disease. Statistically significant risk factors for development of IH were same as for other operations, except the addition of age at the onset of disease [48]. The incidence of IH in children is significantly lower than that in adults, with comparable IH incidence with open and laparoscopic procedures; except increased risk for operations in neonates, laparoscopic fundoplication and open supraumbilical pyloromyotomy [49]. A study based on Swedish Colorectal Cancer Registry has shown the cumulative incidence of incisional hernia as $5.3 \%$ after 5 years of surgery; the risk factors were same as mentioned (vide supra) [50]. Another study has found the incidence at $13 \%$ out of 4579 colon resections [51]. Incidence of IH in cases of 'open abdomen' is high and reaches up to $65 \%$.

Extrapolation of preventive options which have been shown effective in giant ventral hernia repair (including Component Separation Techniques, prophylactic negative pressure wound therapy, synthetic mesh reinforcement and use of Botulinum Toxin Type A to aid in abdominal wall reconstruction) might work effectively in this patient cohort with open abdomen as well [52]. The rate of IH after abdominal cancer operations is high and incidence varies for different diagnoses: urologic/ gynecologic (30\%), colorectal (53\%), and all others (56\%); but with similar risk factors [53]. IHs are common due to postoperative immunosuppression following abdominal organ transplant with nearly one in five patients developing an incisional hernia 5 years after liver or pancreas transplantation. On multivariate analysis, SSI was strongly associated with hernia formation in all groups and its prevention and efficient treatment should be a priority in trying to prevent IH [54].

\section{Fascial dehiscence/burst abdomen}

Another significant factor is fascial dehiscence/ burst abdomen, which is almost invariably followed by $\mathrm{IH}$; regardless of suture material, technique of repair or application of retention sutures. This requires improvement in technique for repairing a burst abdomen. Fascial dehiscence and IH have similar causative factors; but fascial dehiscence occurring within 2 weeks of emergency surgery reflects more about the patient related factors (anemia, hypoproteinemia, intraabdominal sepsis, post-operative abdominal distention, chest infection etc.) while IH occurring much later is more reflective of abdominal closure technique.

\section{Identification of high-risk cases and centralized care}

Risk prediction models have statistically combined significant risk factors to identify high risk patients preoperatively and these have been validated externally [55]. Perhaps the time has come to have centralized care for high risk cases to prevent the formation of IH.

\section{Safety of synthetic mesh in presence of infection and strangulation}

Evidence is accumulating that a synthetic mesh can be safely used in the presence of perforation peritonitis and strangulated bowel [56-60]. The incidence of infection may be high, but the morbidity is acceptable and mesh removal is rarely required [60]. This favorable resistance of the non-absorbable synthetic structure of the polypropylene mesh to infections can be explained by the macro-porous structure of the mesh with pores of diameter larger than 70 microns, which allows contact of bacteria (measuring 1 micron in diameter) with granulocytes and macrophages (diameter of 15-20microns). This facilitates recovery from infections, and results in a high resistance rate to infections [61].

It has been shown in an animal model that there was no persistent inflammation in the contaminated field when the mesh was properly implanted, i.e., spread flat to create a more favorable condition for the penetration of the immune system. Bending or folding the mesh resulted in the creation of dense texture "dead spaces", making it difficult for immune cells to penetrate and leading to the persistence of the inflammatory process. This observation leads to the conclusion that many infections that are related to synthetic materials may be the result of a poor surgical technique [62].

\section{Recent experimental work}

Recent animal experimental research has focused on strengthening of mesh; meshes surface modifications for reducing the adhesive properties to prevent bowel adhesions and 
addition of controlled antibiotic delivery systems for Rifampicin and Gentamycin to prevent implant infections [63-66]. Other experiments include development of stronger suture material (polyurethane), and mesh derived sutures (for better resistance against suture cut-through) for abdominal closure $[67,68]$. Recently biomarkers (proteins assays associated with wound healing, advanced glycation end products/ collagen cross links) have been shown to predict personal hernia risk prior to undergoing an operation; if validated, tests for these can be included in hernia prediction models $[69,70]$.

\section{Conclusion}

Research workers have often lamented about the heterogeneity of patient cohorts, different surgical techniques, different imaging techniques for diagnosis and different follow up periods while reviewing available literature on prevention of IH. But evidence is accumulating that lightweight macro-porous synthetic mesh can be safely used without additional morbidity even in the presence of perforation peritonitis and strangulated bowel; prompting proponents to argue that prophylactic synthetic mesh augmentation should become the standard of care for high-risk patients undergoing midline laparotomy. Although Surgeons have always embraced new technologies; they seem surprisingly slow in using the option of prophylactic mesh augmentation in preventing IH. Fears of seroma formation, foreign body sensation and infection related morbidity are grossly over estimated and easily outweigh the advantage of preventing IH. Now that it is possible to identify high risk patients for development of $\mathrm{IH}$, high quality evidence is available for its prevention and the preventive measures do not require expansive resources; time has come to overcome ingrained bias and convert available knowledge to implementation.

\section{References}

1. Bower C, Roth JS (2013) Economics of abdominal wall reconstruction. Surg Clin North Am 93(5): 1241-1253.

2. Harris HW, Hope WH, Adrales G, Andersen DK, Deerenberg EB, et al. (2018) Contemporary concepts in hernia prevention: Selected proceedings from the 2017. International Symposium on Prevention of Incisional Hernias. Surgery 164(2): 319-326.

3. Itatsu K, Yokoyama Y, Sugawara G, Kubota H, Tojima Y, et al. (2014) Incidence of and risk factors for incisional hernia after abdominal surgery. Br J Surg 101(11): 1439-1447.

4. Allegranzi B, Bischoff P, De Jonge S, Kubilay NZ, Zayed B, et al. (2016) WHO Guidelines Development Group. New WHO recommendations on preoperative measures for surgical site infection prevention: an evidence-based global perspective. Lancet Infect Dis 16(12): e276-e287.

5. Berríos TSI, Umscheid CA, Bratzler DW, Leas B, Stone EC, et al. (2017) Healthcare infection control practices advisory committee. Centers for disease control and prevention guideline for the prevention of surgical site infection, 2017. JAMA Surg 152(8): 784-791.

6. Weiser MR, Gonen M, Usiak S, Pottinger T, Samedy P, Patel D, et al. (2018) Memorial sloan kettering multidisciplinary surgical-site infection reduction team. Effectiveness of a multidisciplinary patient care bundle for reducing surgical-site infections. Br J Surg 105(12): 1680-1687.

7. Nelson RL, Gladman E, Barbateskovic M (2014) Antimicrobial prophylaxis for colorectal surgery. Cochrane Database Syst Rev 9(5): CD001181.
8. Koullouros M, Khan N, Aly EH (2017) The role of oral antibiotics prophylaxis in prevention of surgical site infection in colorectal surgery. Int J Colorectal Dis 32(1): 1-18.

9. Wu XD, Xu W, Liu MM, Hu KJ, Sun YY, et al. (2018) Efficacy of prophylactic probiotics in combination with antibiotics versus antibiotics alone for colorectal surgery: A meta-analysis of randomized controlled trials. J Surg Oncol 117(7): 1394-1404.

10. Heal CF, Banks JL, Lepper PD, Kontopantelis E, van Driel ML (2016) Topical antibiotics for preventing surgical site infection in wounds healing by primary intention. Cochrane Database Syst Rev 11: CD011426.

11. Nelson RL, Kravets A, Khateeb R, Raza M, Siddiqui M, et al. (2018) Topical antimicrobial prophylaxis in colorectal surgery for the prevention of surgical wound infection: a systematic review and meta-analysis. Tech Coloproctol 22(8): 573-587.

12. Elsolh B, Zhang L, Patel SV (2017) The Effect of Antibiotic-Coated Sutures on the Incidence of Surgical Site Infections in Abdominal Closures: A Meta-Analysis. J Gastrointest Surg 21(5): 896-903.

13. Henriksen NA, Deerenberg EB, Venclauskas L, Fortelny RH, Garcia AJM, et al. (2017) Triclosan-coated sutures and surgical site infection in abdominal surgery: the TRISTAN review, meta-analysis and trial sequential analysis. Hernia 21(6): 833-841.

14. Arer IM, Yabanoglu H, Aytac HO, Ezer A (2016) The effect of subcutaneous suction drains on surgical site infection in open abdominal surgery: A prospective randomized study. Ann Ital Chir 87: 49-55.

15. Bunting DM (2010) Port-Site hernia following laparoscopic cholecystectomy. JSLS 14(4): 490-497.

16. Agaba EA, Rainville H, Ikedilo O, Vemulapali P (2014) Incidence of portsite incisional hernia after single-incision laparoscopic surgery. JSLS 18(2): 204-210.

17. Lambertz A, Stüben BO, Bock B, Eickhoff R, Kroh A, et al. (2017) Port-site incisional hernia-A case series of 54 patients. Ann Med Surg (Lond) 14: 8-11.

18. Bosanquet DC, Ansell J, Abdelrahman T, Cornish J, Harries R, et al. (2015) Systematic review and meta-regression of factors affecting midline incisional hernia rates: Analysis of 14,618 patients. PLoS One 10(9): e0138745.

19. Muysoms FE, Antoniou SA, Bury K, Campanelli G, Conze J, et al. (2015) European hernia society guidelines on the closure of abdominal wall incisions. Hernia 19(1): 1-24.

20. Lee L, Khalil AM, Liberman S, Boutros M, Fried GM, et al. (2017) Incidence of incisional hernia in the specimen extraction site for laparoscopic colorectal surgery: systematic review and meta-analysis. Surg Endosc 31(12): 5083-5093.

21. Heimann TM, Swaminathan S, Greenstein AJ, Greenstein AJ, Khaitov S, et al. (2017) Can laparoscopic surgery prevent incisional hernia in patients with crohn's disease: a comparison study of 750 patients undergoing open and laparoscopic bowel resection. Surg Endosc 31(12): 5201-5208.

22. Deerenberg EB, Harlaar JJ, Steyerberg EW, Lont HE, van Doorn HC, et al. (2015) Small bites versus large bites for closure of abdominal midline incisions (STITCH): a double-blind, multicentre, randomised controlled trial. Lancet 386(10000): 1254-1260.

23. Tolstrup MB, Watt SK, Gögenur I (2017) Reduced rate of dehiscence after implementation of a standardized fascial Closure technique in patients undergoing emergency laparotomy. Ann Surg 265(4): 821-826.

24. Henriksen NA, Deerenberg EB, Venclauskas L, Fortelny RH, Miserez M, et al. (2018) Meta-analysis on Materials and techniques for laparotomy closure: The MATCH review. World J Surg 42(6): 1666-1678.

25. Fortelny RH, Baumann P, Thasler WE, Albertsmeier M, Riedl S, et al. (2015) Effect of suture technique on the occurrence of incisional hernia after elective midline abdominal wall closure: study protocol for a randomized controlled trial. Trials 16: 52. 
26. Golling M, Felbinger S, Zielska Z, Maurer K, Baumann P (2016) Do we need to relearn abdominal wall closure: Small stitches. Chirurg 87(9): 744-750.

27. Williams ZF, Tenzel P, Hooks WB $3^{\text {rd }}$, Hope WW (2017) Suture to wound length ratio in abdominal wall closure: how well are we doing? Hernia 21(6): 869-872.

28. Harries RL, Cornish J, Bosanquet D, Rees B, Horwood J, et al. (2016) Hughes abdominal repair trial (HART)-abdominal wall closure techniques to reduce the incidence of incisional hernias: feasibility trial for a multicentre, pragmatic, randomised controlled trial. BMJ Open $7(12)$ : e017235.

29. Kothari R, Thakur R, Sharma D, Agarwal P (2018) Herring bone stitch: knitting to secure abdominal wall closure for emergency midline laparotomy. Gastro Med Res 1(5): 1-8.

30. Jairam AP, Timmermans L, Eker HH, Pierik REGJM, van Klaveren D, et al. (2017) Prevention of incisional hernia with prophylactic onlay and sublay mesh reinforcement versus primary suture only in midline laparotomies (PRIMA): 2-year follow-up of a multicentre, double-blind, randomised controlled trial. Lancet 390(10094): 567-576.

31. Payne R, Aldwinckle J, Ward S (2017) Meta-analysis of randomised trials comparing the use of prophylactic mesh to standard midline closure in the reduction of incisional herniae. Hernia 21(6): 843-853.

32. Cross AJ, Buchwald PL, Frizelle FA, Eglinton TW (2017) Meta-analysis of prophylactic mesh to prevent parastomal hernia. Br J Surg 104(3): 179-186.

33. Rhemtulla IA, Mauch JT, Broach RB, Messa CA, Fischer JP (2018) Prophylactic mesh augmentation: Patient selection, techniques, and early outcomes. Am J Surg 216(3): 475-480.

34. Muysoms FE, Jairam A, López-Cano M, Śmietański M, Woeste G, et al. (2016) Prevention of Incisional Hernias with Biological Mesh: A Systematic Review of the Literature. Front Surg 3: 53.

35. Patel SV, Zhang L, Chadi SA, Wexner SD (2017) Prophylactic mesh to prevent parastomal hernia: a meta-analysis of randomized controlled studies. Tech Coloproctol 21(1): 5-13.

36. Köckerling F, Alam NN, Antoniou SA, Daniels IR, Famiglietti F, et al. (2018) What is the evidence for the use of biologic or biosynthetic meshes in abdominal wall reconstruction? Hernia 22(2): 249-269.

37. Williams NS, Hotouras A, Bhan C, Murphy J, Chan CL (2015) A casecontrolled pilot study assessing the safety and efficacy of the Stapled Mesh stomA Reinforcement Technique (SMART) in reducing the incidence of parastomal herniation. Hernia 19(6): 949-954.

38. Muíño CR, Díez JL, Martínez A, Huertas F, Segura I, et al. (2017) Preventing parastomal hernias with systematic intraperitoneal specifically designed mesh. BMC Surg 17(1): 41

39. Antoniou SA, Agresta F, Garcia Alamino JM, Berger D, Berrevoet F, et al. (2018) European hernia society guidelines on prevention and treatment of parastomal hernias. Hernia 22(1): 183-198.

40. Köhler G, Koch O0, Antoniou SA, Lechner M, Mayer F, et al. (2014) Prevention of subcutaneous seroma formation in open ventral hernia repair using a new low-thrombin fibrin sealant. World J Surg 38(11): 2797-2803

41. Yildız I, Koca YS (2017) What kind of incision should be made to reduce the risk of incisional hernia in kidney transplantation? Ann Transplant 22: 689-693.

42. Kroese LF, de Smet GH, Jeekel J, Kleinrensink GJ, Lange JF (2016) Systematic review and meta-analysis of extraperitoneal versus transperitoneal colostomy for preventing parastomal hernia. Dis Colon Rectum 59(7): 688-695.

43. Hardt J, Seyfried S, Weiß C, Post S, Kienle P, et al. (2016) A pilot singlecentre randomized trial assessing the safety and efficacy of lateral pararectus abdominis compared with transrectus abdominis muscle stoma placement in patients with temporary loop ileostomies: the PATRASTOM trial. Colorectal Dis 18(2): 081-090.

44. Melich G, Lim DR, Hur H, Min BS, Baik SH, et al. (2016) Prevention of perineal hernia after laparoscopic and robotic abdominoperineal resection: review with illustrative case series of internal hernia through pelvic mesh. Can J Surg 59(1): 54-58.

45. Bouvier A, Rat P, Drissi CF, Bonnetain F, Lacaine F, et al. (2014) For the federation of surgical research. Abdominal binders after laparotomy: review of the literature and French survey of policies. Hernia 18(4): 501-506.

46. Pommergaard HC, Burcharth J, Danielsen A, Angenete E, Haglind E, et al. (2014) No consensus on restrictions on physical activity to prevent incisional hernias after surgery. Hernia 18(4): 495-500.

47. Khorgami Z, Shoar S, Laghaie B, Aminian A, Hosseini AN, et al. (2013) Prophylactic retention sutures in midline laparotomy in high-risk patients for wound dehiscence: a randomized controlled trial. J Surg Res 180(2): 238-243.

48. Heimann TM, Swaminathan S, Greenstein AJ, Steinhagen RM (2018) Incidence and factors correlating with incisional hernia following open bowel resection in patients with inflammatory bowel disease: a review of 1000 patients. Ann Surg 267(3): 532-536.

49. Tanaka K, Misawa T, Ashizuka S, Yoshizawa J, Akiba T, et al. (2018) Risk Factors for Incisional Hernia in Children. World J Surg 42(7): 2265-2268.

50. Söderbäck H, Gunnarsson U, Hellman P, Sandblom G (2018) Incisional hernia after surgery for colorectal cancer: a population-based register study. Int J Colorectal Dis 33(10): 1411-1417.

51. Alli VV,Zhang J, Telem DA (2018) Impact of incisional hernia development following abdominal operations on total healthcare cost. Surg Endosc 32(5): 2381-2386.

52. Berrevoet F (2018) Prevention of incisional hernias after open abdomen treatment. Front Surg 5: 11.

53. Baucom RB, Ousley J, Beveridge GB, Phillips SE, Pierce RA, et al. (2016) Cancer survivorship: Defining the incidence of incisional hernia after resection for intra-abdominal malignancy. Ann Surg Oncol 23(Suppl 5): 764-771.

54. Smith CT, Katz MG, Foley D, Welch B, Leverson GE, et al. (2015) Incidence and risk factors of incisional hernia formation following abdominal organ transplantation. Surg Endosc 29(2): 398-404.

55. Cherla DV, Moses ML, Mueck KM, Hannon C, Ko TC, et al. (2017) External validation of the HERNIA score: An observational study. J Am Coll Surg 225(3): 428-434

56. Kurmann A, Barnetta C, Candinas D, Beldi G (2013) Implantation of prophylactic nonabsorbable intraperitoneal mesh in patients with peritonitis is safe and feasible. World J Surg 37(7): 1656-1660.

57. Argudo N, Pereira JA, Sancho JJ, Membrilla E, Pons MJ, et al. (2014) Prophylactic synthetic mesh can be safely used to close emergency laparotomies, even in peritonitis. Surgery 156(5): 1238-1244.

58. Atema JJ, de Vries FE, Boermeester MA (2016) Systematic review and meta-analysis of the repair of potentially contaminated and contaminated abdominal wall defects. Am J Surg 212(5): 982-995.

59. Dumanian GA, Lanier ST, Souza JM, Young MW, Mlodinow AS, et al. (2018) Mesh sutured repairs of contaminated incisional hernias. Am J Surg 216(2): 267-273.

60. Pandey H, Thakur DS, Somashekar U, Kothari R, Agarwal P, et al. (2018) Use of polypropylene mesh in contaminated and dirty strangulated hernias: Short term results. Hernia 22(6):1045-1050.

61. Klosterhalfen B, Klinge U (2013) Retrieval study at 623 human mesh explants made of polypropylene--impact of mesh class and indication for mesh removal on tissue reaction. J Biomed Mater Res B Appl Biomater 101(8): 1393-1399. 
62. Bury K, Smietański M, Justyna B, Gumiela P, Smietańska AI, et al. (2014) Effects of macroporous monofilament mesh on infection in a contaminated field. Langenbecks Arch Surg 399(7): 873-877.

63. Plencner M, East B, Tonar Z, Otáhal M, Prosecká E, et al. (2014) Abdomina closure reinforcement by using polypropylene mesh functionalized with poly- $\varepsilon$-caprolactone nanofibers and growth factors for prevention of incisional hernia formation. Int J Nanomedicine 9: 3263-3277.

64. Aydin 0, Aydinuraz K, Agalar F, Sahiner IT, Agalar C, et al. (2017) The effect of thymoquinone coating on adhesive properties of polypropylene mesh. BMC Surg 17(1): 40

65. Reinbold J, Hierlemann T, Urich L, Uhde AK, Müller I, et al. (2017) Biodegradable rifampicin-releasing coating of surgical meshes for the prevention of bacterial infections. Drug Des Devel Ther 11:2753-2762.

66. Wiegering A, Sinha B, Spor L, Klinge U, Steger U, et al. (2014) Gentamicin for prevention of intraoperative mesh contamination: demonstration of high bactericide effect (in vitro) and low systemic bioavailability (in vivo). Hernia 18(5): 691-700.
67. Bellón JM, Pérez LP, Simón AR, Sotomayor S, Pérez KB, et al. (2014) New suture materials for midline laparotomy closure: an experimental study. BMC Surg 14: 70.

68. Souza JM, Dumanian ZP, Gurjala AN, Dumanian GA (2015) (In vivo) Evaluation of a novel mesh suture design for abdominal wall closure. Plast Reconstr Surg 135(2): 322e-330e.

69. Böhm J, Pianka F, Stüttgen N, Rho J, Gigic B, et al. (2017) Discovery of novel plasma proteins as biomarkers for the development of incisional hernias after midline incision in patients with colorectal cancer: The ColoCare study. Surgery 161(3): 808-817.

70. Harlaar JJ, Eker HH, Vakalopoulos KA, Cabezas MC, van der Ham AC, et al. (2017) Advanced glycation end products as a biomarker for incisional hernia. Hernia 21(4): 537-541.
(C) Creative Commons Attribution 4.0 International License

For possible submissions Click Here

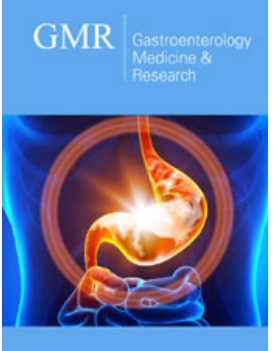

Gastroenterology Medicine \& Research

\section{Benefits of Publishing with us}

- High-level peer review and editorial services

- Freely accessible online immediately upon publication

- Authors retain the copyright to their work

- Licensing it under a Creative Commons license

- Visibility through different online platforms 